\title{
Using Individual, ApoE Genotype-Based Dietary and Physical Activity Advice to Promote a Healthy Lifestyle: Associations between Psychological, Behavioral and Clinical Factors
}

\author{
HL Hietaranta Luoma ${ }^{1 *}$, HT Luomala ${ }^{2}$, R Tahvonen $^{3}$, H Puolijoki ${ }^{4}$, L Koivusilta ${ }^{5}$ and A Hopia ${ }^{1}$ \\ ${ }^{1}$ Functional Foods Forum, University of Turku, Finland \\ ${ }^{2}$ Department of Marketing, University of Vaasa, Finland \\ ${ }^{3}$ Natural Resources Institute Finland (Luke) (earlier MTT Agrifood Research Finland), Finland \\ ${ }^{4}$ Central Hospital of Southern Ostrobothnia, Seinäjoki, Finland \\ ${ }^{5}$ School of Health Sciences, University of Tampere, Finland
}

Received: August 17, 2015; Accepted: October 07, 2015; Published: October 18, 2015

*Corresponding author: Hanna-Leena Hietaranta-Luoma, Functional Foods Forum, University of Turku, Kampusranta 9 C, 60320 Seinäjoki, Finland, Tel: +358 50324 6585; E-mail: hlhieta@utu.fi

\begin{abstract}
Objective: The aim of this study was to combine the results of three different papers reporting psychological, behavioral, and clinical changes in risk factors for Cardiovascular Disease (CVD) in the context of ApoE based genetic feedback, and study associations between their variables. In the analysis, we focused on the statistically clearest changes $(p<0.05)$ : cardiovascular threat experience, dietary fat quality, triglycerides and waist circumference.
\end{abstract}

Design: A one-year, explanatory controlled intervention study in Finland.

Settings: Psychological, behavioral, and clinical changes were measured three-four times during the intervention (T0, T1, T2, and T3). Hierarchical multiple regression, a forward stepwise method, was used to analyze predictors for the changes in cardiovascular threat experience (T0-T1), dietary fat quality (T0-T1), triglyceride values (T0-T2) and waist circumference (T0-T2).

Subjects: Healthy adults, aged 20-67 years $(n=106)$ of which 16 belonged to the high-risk group $(\varepsilon 4+), 35$ to the low-risk group $(\varepsilon 4-)$ and 55 to the control group.

Results: The change in Body Mass index was the most significant predictor for the change in triglyceride values and waist circumference $(p<0.001)$. The group $(\varepsilon 4+, \varepsilon 4-$, control $)$ was a significant predictor for the change in dietary fat quality $(p=0.024)$ and for the change in waist circumference $(p=0.027)$.

Conclusion: Changes in psychological predictors (anxiety and threat experience, motivation), in health and taste attitudes, and health behaviors (diet, alcohol consumption, physical activity) did not directly explain the changes in triglyceride values and waist circumference. However, the change in threat experience may affect the change in triglycerides through total and HDL cholesterol. Clinical changes seemed to accumulate.

Keywords: Predictor; Clinical; Behavioral; Psychological; Genetic information; ApoE; Threat experience; Dietary fat quality; Triglycerides; Waist circumference

\section{Introduction}

It has been suggested that individually tailored, genotypebased nutrition and health advice will become more common in the near future [1]. However, there are limited number of studies focusing on the psychological and behavioral effects of gene information and their effect on measured risk factors. In addition, an often ignored standpoint in health behavior interventions is psychological factors, which may also have an impact on health behavior changes. For example, Bonnet et al. 2005 [2], found that increased anxiety and depression experience predict an unhealthy diet and low physical activity. Indeed, genetic information can cause harmful psychological effects like fatalism, anxiety, depression, threat and stress, and consequently the desired health behavior change will not take place $[3,4]$. According to Witte's (2001) Extended Parallel Process Model (EPPM), health behavior change may happen, if the health threat is perceived as a danger, but not yet as a fear [5]. In addition, intentions to eat healthily and have better health-related attitudes have been shown to be good predictors of healthy food choices in diets [610]. Although the basic assumption is that attitudes and beliefs in some way guide, influence, direct, shape, and predict health behavior [11], it is still questionable how many of these attitudes and beliefs affect our responses to dietary recommendations [8]. 
This study examined the associations between psychological, behavioral and clinical changes in the context of genetic feedback. This paper concentrates on the four statistically clearest changes $(p<0.05)$, which have been presented in our previous papers [12-14]. These are: the effect of ApoE genotype-based health information on changes in a threat experience (T0-T1), dietary fat quality (T0-T1), triglycerides (T0-T2) and waist circumference (T0-T2). To our knowledge, there have been no controlled studies of using personalized health information based on the apoE genotype to promote a healthy lifestyle, which regards on psychological, health behavioral and clinical aspects and their associations.

\section{Material and Methods}

\section{Overview}

Altogether, 122 adults, aged between 20 - 67 years participated in one-year, single-blinded, explanatory intervention study. The participants included in the study were healthy, had no long-term medication (e.g., diabetes, cholesterol, blood pressure, psychiatric medication) or chronic conditions (e.g., diabetes or mental disorders). Other inclusion criteria included: blood pressure under $160 / 99 \mathrm{~mm} / \mathrm{Hg}$, hemoglobin over $120 \mathrm{~g} / \mathrm{l}$, proper kidney, liver and thyroid function (fP-Krea < 115 umol; p-ALAT 10 - 35 U/I (women), 10 - 50 U/I (men);P-TSH 0.30 - 4.20 mU/l) Individuals who were overweight (BMI $20-35 \mathrm{~kg} / \mathrm{m}^{2}$ ), had slight hyperlipidemia (total cholesterol $<8 \mathrm{mmol} / \mathrm{l}$, triglycerides $<4.5$ $\mathrm{mmol} / \mathrm{l}$ ) or impaired glucose tolerance (fasting glucose $<7.0$ $\mathrm{mmol} / \mathrm{l}$ and glucose two hours after challenge $<11.0 \mathrm{mmol} / \mathrm{l})$ were included in the study.

The participants were randomized into a control $(\mathrm{n}=61)$ and an intervention group $(n=61)$ before the genetic results were available. There were 40 participants in E4- group (included ApoE genotypes $3 / 4$ and $4 / 4$ ) and 21 participants in the $\varepsilon 4+$ group (included apoE genotypes $2 / 3$ and $3 / 3$ ). The control group included 61 participants (included ApoE genotypes 3/4, 4/4, 2/3, $3 / 3$ and $2 / 2$ ).

The baseline and follow-up assessments included detailed measurements of psychological (threat and anxiety experience, stage of change), [12] behavioral (dietary fat quality, consumption of vegetables, - high fat/sugar foods and -alcohol, physical activity and health and taste attitudes) [13] and clinical factors [14]. Measures were taken at the baseline (T0), after genetic feedback (T1), after six months (T2) and after 12 months (T3). During the intervention, six different communication sessions (lectures on healthy lifestyle and nutrigenomics, health messages by mail, and personal discussion with the doctor) were arranged. The intervention groups ( $\varepsilon 4+$ and $\varepsilon 4-)$ received their ApoE genotype information and health message at the beginning of the intervention, but the control group received their ApoE genotype results after the intervention.

Of all 122 participants, five people dropped out and four participants who had started cholesterol, blood pressure, or diabetes medication during the intervention; seven participants who had missing values in their answers or turned out to be outliers were excluded. The effects of the intervention were compared between $\varepsilon 4+$ group (high-risk group, $\mathrm{n}=16$, including ApoE 3/4 and 4/4), E4- group (low-risk group, $n=35$, including apoE $2 / 3$ and $3 / 3$ ) and the control group ( $\mathrm{n}=56$ (55)), including ApoE 2/2, 2/3, 3/3, 3/4 and 4/4 genotypes). A detailed procedure of this intervention has been described in our previous papers $[12,13]$.

\section{Explained changes and predictors}

The explained changes were the cardiovascular threat experience (T0-T1) based on the Risk Behavior Diagnostic Scale (RBD) [5], the dietary fat quality (T0-T1) based on a questionnaire from the Finnish Heart Association [15], triglyceride values (T0T2) [14] and waist circumference (T0-T2) [14].

The predictors were the group $(\varepsilon 4+, \varepsilon 4-$, control), the sex, age, psychological assessments (Trait-Anxiety (T0), State Anxiety (T0-T1), Stage of change (T0-T1), behavioral assessments (T0T1: consumption of vegetables, high fat, sugar foods, alcohol and physical activity), attitude assessments (T0-T1: Health And Taste Attitude scales (HTAS [6]) and clinical markers (T0T2: Total, HDL cholesterol, blood glucose $(0 \mathrm{~h})$, blood pressure, BMI, body Fat Percentage). In addition, the explained changes (threat experience, dietary fat quality, triglycerides and waist circumference) were included as predictors, when explaining the other changes that were statistically clearest. Psychological, behavioral, and clinical assessments are described in more detail in our previous articles [12-14].

\section{Statistical analysis}

Preliminary analyzes (exploring normality, missing values, and outliers) were conducted before the final analyzes.

The clearest changes (threat experience, dietary fat quality, triglycerides, waist circumference) were the main intervention effects, which were analyzed by a combination of repeatedmeasures ANOVA and a between-groups ANOVA; General linear model (repeated measures). The familywise error (a Type 1 error) was controlled by Bonferroni correction as setting the alpha values 0.017 in the psychological analyzes [12] and 0.005 in the clinical analyzes [14].

Changes $(\Delta)$ between T0 and T1/T2 measuring points were calculated for hierarchical multiple regression analysis, which was used to analyze predictors of the outcomes. In regression analysis, the variable indicating the group $(\varepsilon 4+, \varepsilon 4-$, control) was forced into the model, after which, the predictors were included in a forward stepwise analysis in the above-mentioned order to find out the statistically strongest predictors (models (a) to (c)). Total and LDL cholesterol were highly correlated (multicollinearity), and therefore only total cholesterol was included in the analyses.

Data management and analysis were performed using SPSS (IBM Corp. Released 2012. IBM SPSS Statistics for Windows, Version 22.0. Armonk, NY: IBM Corp.).

\section{Results}

\section{Characteristics of participants}

Of the 106 participants who completed this present study, 
$69.2 \%$ were female and the mean age was 47.0 (SD 12.1). Approximately one-fourth (26.2\%) of the participants had an E4 allele, placing them at an increased risk for CVD and only one individual had ApoE 2/2 genotype. There was no ApoE 2/4 genotype among participants (Table 1).

\section{The intervention effects}

Taking into account all measurements and groups $(\varepsilon 4+$, $\varepsilon 4$ - and control), the clearest effects of the intervention was in threat experience, dietary fat quality, triglycerides and waist circumference. The intervention had an almost statistically significant effects on threat experience ( $p=0.034$; alpha level $0.017)$, triglycerides $(p=0.038)$ and waist circumference ( $p$ $=0.027$; alpha level 0.005) and a significant effect on dietary fat quality ( $p=0.048$; alpha level 0.05 ). The threat experience increased mostly in the $\varepsilon 4+$ group after the genetic feedback, but it decreased after 12 months, although it remained at a higher level compared to the baseline (T0). Moreover, dietary fat quality, triglyceride values, and waist circumference improved more in the $\varepsilon 4+$ group than in the $\varepsilon 4$ - and control groups after genetic feedback. Table 2 summarizes these effects. The results have been presented in detail in our previous articles [12-14]. The Intervention had no effects on other serum lipids (total-, LDL-, HDL cholesterol), as they stayed almost constant during the intervention [14].

\section{Predictors behind the changes in CVD risk factors}

Change $(\Delta \mathrm{T} 0-\mathrm{T} 1)$ in threat experience was best explained by the model (c) (15.8\%; $p=0.005)$, which included the group and changes (T0-T2) in the systolic blood pressure and total cholesterol. The strongest predictor was the systolic blood pressure (T0-T2) $(9.4 \% ; p=0.007 ; \beta=0.290)$

The change in Dietary fat quality $(\Delta \mathrm{T} 0-\mathrm{T} 1)$ was best explained by the model (b) (16.0\%; $p=0.002)$, which included the group and body fat percentage (T0-T2). The strongest predictor was the body fat percentage $(9.3 \% ; p=0.005 ; \beta=-0.307)$.

Change $(\Delta \mathrm{T} 0-\mathrm{T} 2)$ in waist circumference was best explained by the model (b) $(28.8 \% ; p<0.001)$, which included the group and BMI (T0-T2), the strongest predictor being BMI (21.9\%; $p<$ $0.001 ; \beta=0.471)$.

Change $(\Delta \mathrm{T} 0-\mathrm{T} 2)$ in triglycerides was best explained by the model (c) (25.6\%; $p<0.001)$, which included the group and changes (T0-T2) in BMI and HDL cholesterol, the strongest predictor being the BMI (19.5\%; $p<0.001 ; \beta=0.464)$ (Table 3).

The hierarchical regression analyzes also revealed some statistically significant interaction effects on the change in triglyceride values, which have been presented in Figure 1.

\section{Discussion}

This one-year intervention study using ApoE genotype-based health information to promote healthy lifestyles in healthy adults had some effects on psychological, behavioral, and clinical factors. However, changes in triglycerides and waist circumference were not directly explained by the changes in attitudes or the psychological and health behavioral factors. However, the change in threat experience seemed to affect a change in triglycerides through the total and HDL cholesterol.

The BMI was found to be the strongest predictor of changes in the triglycerides and waist circumference, which indicates that if the BMI decreases the triglyceride values and waist circumference also decreases. In addition, body fat percentage, total and HDL cholesterol had interactional effects on the triglycerides and waist circumference. These results are in line with those of previous studies, which have found that risk factors for cardiovascular diseases tend to accumulate [16-22]. It has also been shown that unhealthy lifestyle behaviors (e.g. physical inactivity, smoking, excessive consumption of alcohol and saturated fat and low consumption of vegetables) are closely linked to an increased risk of cardiovascular diseases [16,17,23,24]. However, our study was unable to demonstrate that changes in clinical markers (e.g. triglycerides and waist circumference) depend on changes in health behaviors. One possible explanation could be the small group sizes. Nevertheless, there were several small, favorable changes in health behaviors (e.g. vegetables consumption, alcohol consumption and fatty and sugary food consumption) that together could affect triglyceride values and waist

Table 1: Demographics and ApoE genotypes of the included participants (106).

\begin{tabular}{|c|c|c|c|}
\hline & Total & E4+ Group & E4- Group \\
\hline Number of Participants (n) & 106 & 16 & 35 \\
\hline Age (Years, mean(SD)) & $47.0(12.1)$ & $47.8(12.3)$ & $47.3(11.2)$ \\
\hline Men (Years, mean(SD)) & $53.3(11.4)$ & & \\
\hline Women (Years, mean(SD)) & $44.2(11.4)$ & & $85.7(30)$ \\
\hline Female, Sex \%, (n) & $69.2(74)$ & $62.5(10)$ & \\
\hline ApoE genotype \%, (n) & & & \\
\hline E3/E3 & $59.8(64)$ & $0.9(0)$ & $77.1(27)$ \\
\hline E3/E4 & $24.3(26)$ & $93.8(15)$ & $0(0)$ \\
\hline E2/E3 & $13.1(14)$ & $0(0)$ & $19.6(11)$ \\
\hline E4/E4 & $1.9(2)$ & $6.2(1)$ & $10.7(6)$ \\
\hline E2/E2 & $0.9(1)$ & $0(0)$ & $0(0)$ \\
\hline
\end{tabular}

Citation: Hietaranta Luoma HL, Luomala HT, Tahvonen R, Puolijoki H, Koivusilta L, et al. (2015) Using Individual, ApoE Genotype-Based Dietary and Physical Activity Advice to Promote a Healthy Lifestyle: Associations between Psychological, 
Table 2: The statistically clearest effects of the intervention. Changes in cardiovascular threat experience, dietary fat quality, triglyceride values and waist circumference between $\varepsilon 4+, \varepsilon 4-$ and control groups.

\begin{tabular}{|c|c|c|c|c|c|c|}
\hline & & \multirow{2}{*}{\begin{tabular}{|l} 
Without \\
Adjustment
\end{tabular}} & \multicolumn{4}{|c|}{ Adjusted for Baseline Score } \\
\hline & & & Baseline (T0) & 10 Week (T1) & Six Months (T2) & 12 Months (T3) \\
\hline Measure and Range & Group & Mean & Mean & Mean (SE) & Mean (SE) & Mean (SE) \\
\hline $\begin{array}{l}\text { Cardiovascular threat } \\
\text { experience, RBD Scale } \\
36-36\end{array}$ & $\begin{array}{l}\varepsilon 4+(n=16) \\
\varepsilon 4-(n=35) \\
\text { Control }(n=56)\end{array}$ & $\begin{array}{l}4.6(8.3) \\
5.9(7.5) \\
4.5(6.6)\end{array}$ & $\begin{array}{l}5.0 \\
5.0 \\
5.0\end{array}$ & $\begin{array}{l}1.5(1.8)^{\mathrm{a}} \\
7.0(1.2)^{\mathrm{a}} \\
4.2(1.0)\end{array}$ & $\begin{array}{l}\text { NA } \\
\text { NA } \\
\text { NA }\end{array}$ & $\begin{array}{l}2.5(1.8) \\
6.7(1.2) \\
5.7(1.0)\end{array}$ \\
\hline $\begin{array}{l}\text { Dietary fat quality, Scale } \\
0-27\end{array}$ & $\begin{array}{l}\varepsilon 4+(n=16) \\
\varepsilon 4-(n=35) \\
\text { Control }(n=56)\end{array}$ & $\begin{array}{l}14.7(5.1) \\
16.3(6.5) \\
16.7(5.2)\end{array}$ & $\begin{array}{l}16.3 \\
16.3 \\
16.3\end{array}$ & $\begin{array}{l}20.1(1.0)^{\mathrm{b}} \\
18.1(0.7) \\
17.3(0.5)^{\mathrm{b}}\end{array}$ & $\begin{array}{l}20.4(0.9) \\
18.5(0.6) \\
17.6(0.5)\end{array}$ & $\begin{array}{l}18.7(0.9) \\
18.3(0.6) \\
17.8(0.5)\end{array}$ \\
\hline Triglycerides (mmol/l) & $\begin{array}{l}\varepsilon 4+(n=16) \\
\varepsilon 4-(n=35) \\
\text { Control }(n=56)\end{array}$ & $\begin{array}{l}1.10(0.69) \\
1.06(0.46) \\
1.28(0.63)\end{array}$ & $\begin{array}{l}1.17 \\
1.17 \\
1.17\end{array}$ & $\begin{array}{l}\text { NA } \\
\text { NA } \\
\text { NA }\end{array}$ & $\begin{array}{l}0.87(0.08)^{c} \\
1.08(0.06) \\
1.11(0.04)^{c}\end{array}$ & $\begin{array}{l}0.89(0.09) \\
1.07(0.06) \\
1.04(0.05)\end{array}$ \\
\hline $\begin{array}{l}\text { Waist circumference } \\
(\mathrm{cm})\end{array}$ & $\begin{array}{l}\varepsilon 4+(n=16) \\
\varepsilon 4-(n=35) \\
\text { Control }(n=55)\end{array}$ & $\begin{array}{l}84.5(10.6) \\
83.9(9.9) \\
85.9(11.2)\end{array}$ & $\begin{array}{l}86.1 \\
86.1 \\
86.1\end{array}$ & $\begin{array}{l}\text { NA } \\
\text { NA } \\
\text { NA }\end{array}$ & $\begin{array}{l}83.6(1.00)^{\mathrm{d}} \\
85.2(0.73) \\
86.6(0.54)^{\mathrm{d}}\end{array}$ & $\begin{array}{l}85.5(1.02) \\
86.6(0.69) \\
87.6(0.56)\end{array}$ \\
\hline
\end{tabular}

General linear model (repeated measure) was used to analyze effects of the intervention.

Statistical significance has tested from adjusted score.

NOTE: In threat experience, the lower the score, the more threat people feel.

NOTE: In dietary fat quality, the higher the score, the more dietary contains unsaturated fat.

SE: Standard Error

NA: Not Analyzed

\#: Two weeks after receiving gene results

a: $P=0.034$ (alpha level 0.017 )

$\mathrm{b}: p=0.048$ (alpha level 0.05 )

c: $p=0.038$ (alpha level 0.005 )

$\mathrm{d}: p=0.027$ (alpha level 0.005 )

Table 3: Hierarchical multiple linear regression analysis. Predictors for changes in threat experience, dietary fat quality, triglycerides and waist circumference.

\begin{tabular}{|c|c|c|c|c|c|c|c|}
\hline $\begin{array}{l}\text { Explained change } \\
\text { (Dependent variable) }\end{array}$ & Predictors & Model R ${ }^{2}$ & $p\left(R^{2}\right)$ & $\mathbf{R}^{2}$ change & $p$ (change) & $\boldsymbol{\beta}$ & Single Predictor \\
\hline $\begin{array}{l}\text { Threat Experience } \\
(\Delta \mathrm{T} 0-\mathrm{T} 1)\end{array}$ & $\begin{array}{l}\text { Model (a) } \\
\text { Model (b) } \\
\text { Model (c) }\end{array}$ & $\begin{array}{l}0.006 \\
0.100 \\
0.158\end{array}$ & $\begin{array}{l}0.498 \\
0.020 \\
0.005\end{array}$ & $\begin{array}{l}0.006 \\
0.094 \\
0.058\end{array}$ & $\begin{array}{l}0.498 \\
0.007 \\
0.028\end{array}$ & $\begin{array}{l}0.093 \\
0.290 \\
0.242\end{array}$ & $\begin{array}{l}\text { Group } \\
\text { Blood Pressure, systolic } \\
\text { Total Cholesterol }\end{array}$ \\
\hline $\begin{array}{l}\text { Dietary Fat Quality } \\
(\Delta \mathrm{T} 0-\mathrm{T} 1)\end{array}$ & $\begin{array}{l}\text { Model (a) } \\
\text { Model (b) }\end{array}$ & $\begin{array}{l}0.066 \\
0.160\end{array}$ & $\begin{array}{l}0.024 \\
0.002\end{array}$ & $\begin{array}{l}0.066 \\
0.093\end{array}$ & $\begin{array}{l}0.024 \\
0.005\end{array}$ & $\begin{array}{l}0.226 \\
-0.307\end{array}$ & $\begin{array}{l}\text { Group } \\
\text { Body Fat Percentage }\end{array}$ \\
\hline Triglycerides ( $\Delta \mathrm{T} 0$-T2) & $\begin{array}{l}\text { Model (a) } \\
\text { Model (b) } \\
\text { Model (c) }\end{array}$ & $\begin{array}{l}0.014 \\
0.209 \\
0.256\end{array}$ & $\begin{array}{l}0.319 \\
<0.001 \\
<0.001\end{array}$ & $\begin{array}{l}0.014 \\
0.195 \\
0.047\end{array}$ & $\begin{array}{l}0.319 \\
<0.001 \\
0.043\end{array}$ & $\begin{array}{l}0.054 \\
0.464 \\
-0.219\end{array}$ & $\begin{array}{l}\text { Group } \\
\text { BMI } \\
\text { HDL-Cholesterol }\end{array}$ \\
\hline $\begin{array}{l}\text { Waist Circumference } \\
(\Delta \mathrm{T} 0-\mathrm{T} 2)\end{array}$ & $\begin{array}{l}\text { Model (a) } \\
\text { Model (b) }\end{array}$ & $\begin{array}{l}0.069 \\
0.288\end{array}$ & $\begin{array}{l}0.027 \\
<0.001\end{array}$ & $\begin{array}{l}0.069 \\
0.219\end{array}$ & $\begin{array}{l}0.027 \\
<0.001\end{array}$ & $\begin{array}{l}0.205 \\
0.471\end{array}$ & $\begin{array}{l}\text { Group } \\
\text { BMI }\end{array}$ \\
\hline
\end{tabular}

Stepwise method was used to analyze predictors. Exception was the group, where the method was enter

$\beta$-values (coefficient)

Single predictor is an addition to the previous model.

NOTE: Explained change $(\Delta \mathrm{T} 0-\mathrm{T} 1 /(\Delta \mathrm{T} 0-\mathrm{T} 2)$ were not included in the model.

NOTE: Threat experience increases, when scores decreases.

Threat Experience ( $\Delta \mathrm{T} 0-\mathrm{T} 1)$ : Model (a): group ( $\varepsilon 4+, \varepsilon 4-$ and control group); Model (b): group and systolic blood pressure (T0-T2); Model (c): group, systolic blood pressure (T0-T2) and total cholesterol (T0-T2)

Dietary Fat Quality ( $\Delta \mathrm{T} 0-\mathrm{T} 1)$ : Model (a): group; Model (b): group and body fat percentage (T0-T2)

Triglyceride ( $\Delta$ T0-T2): Model (a): group; Model (b): group and BMI (T0-T2); Model (c): group, BMI (T0-T2) and HDL-cholesterol (T0-T2)

Waist Circumference $(\Delta \mathrm{T} 0$-T2): Model (a): group; Model (b): group and BMI (T0-T2)

circumference, but not alone in statistically detectable degree. It may also be possible that the response toward dietary fat quality indeed is different among apoE genotypes, which supports our expectation and previous studies [25]. The change in dietary fat quality may have affected the change in triglyceride values in $\varepsilon 4+$ group, but not in E4- group, but due to the small group sizes it was not possible to do a regression analysis separately in each group. In addition, there is always the possibility of an optimistic bias -effect [26], which means that individuals tend to report less likely negative events (e.g. alcohol consumption), and more likely 


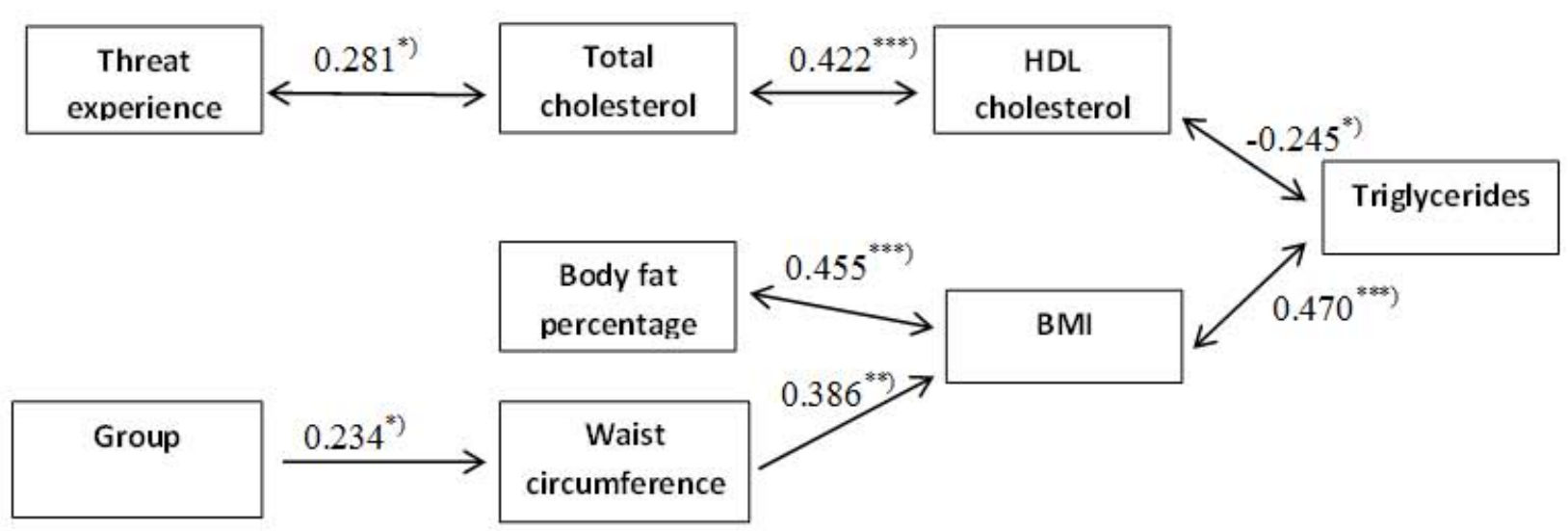

Figure 1: Partial correlations of changes $(\Delta)$ based on hierarchical regression analyzes. Possible interaction-effects on triglyceride values *) $p<0.05$, ${ }^{* *)} p<0.01,{ }^{* * *)} p<0.001$.

positive events (e.g. vegetables consumption).

Further, the present study did not find any connection between attitudinal changes and behavioral changes. Our previous study showed that genetic feedback did not affect health and taste attitudes, and the change in dietary fat quality was short-term [13]. The results of the present and our previous studies imply that behavioral changes (e.g. dietary fat quality) can occur without any attitudinal or psychological changes, but any long-term and permanent change may demand a change in attitude. Although several studies have suggested that health attitudes are closely linked to health behavior [6-8,10,27], controversial results have also been found [28]. The study of Lloyd et al. 1993 [28], observed that participants, who consumed high-fat diets had a similar attitude to dietary change (to a low-fat and more healthful diet) compared with those consuming lowfat diets. The link between attitudes and health behavior is not so unambiguous, and according to Glassman et al. [29], attitudes affect future behaviors, if they are easy to recall, stable over time, and decisive instead of ambivalent. In our study, the focus was on the change in attitudes, so perhaps because the participants expressed ambivalent attitudes this could be one reason for the link between attitudes and health behavior not being shown.

Our previous findings add to a growing body of literature on the interaction of dietary changes and serum lipids [14] concluding that ApoE genotype-based health information had an effect on triglycerides, but not on other serum lipids. CarvalhoWells et al. [30] study also observed greater responsive in triglyceride content, but not in other serum lipids to dietary fat manipulation among ApoE 3/4 genotypes compared with the ApoE 3/3 genotype. However, our present study observed that a change in threat experience was associated with the change in triglycerides through the total and HDL cholesterol. This may imply that an increase in threat experience affected the decrease of triglyceride values, which supports our aim of presenting a health message. According to Witte [5] a health message works when it brings about a suitable amount of fear, but also allows the individual to feel that he/she has enough self-efficacy to follow the proposed action.
Due to the very pioneering nature of this study, it has several limitations (e.g. strict inclusion criteria and small group sizes, only one gene marker, not validated dietary questionnaires, lack of background variables), which have been discussed in our previous studies [12-14]. It is also known that ApoE 2/2 affects the increased triglyceride levels and causes familial dysbetalipoproteinemia (type III hyperlipoproteinemia) [31], but due to small group sizes and only one individual with the ApoE $2 / 2$ and 14 individuals with the ApoE $2 / 3$ genotypes, it wasn't possible to do separate analysis for those groups. However, those individuals' serum lipids were equal level with the carriers of ApoE 3/3. In addition, the variation of measuring times (T0, T1, $\mathrm{T} 2$ and $\mathrm{T} 3$ ) in different predictors (psychological vs. behavioral and clinical) produces some challenges when analyzing the influence of the predictors.

The permanent health behavior change may depend on attitudes and other psychological factors (e.g. motivation) and people may also differ between their Health-Related Motive Orientations (HRMO), which can have effects on their health behavior [32,33]. Therefore, further studies, including several psychological factors, attitudes, the health-related meaning aspect, larger group sizes, and longer follow-up times are recommended.

To conclude, this study has reportedly demonstrated for the first time some associations between psychological, behavioral, and clinical changes in the context of genetic feedback. In general, the changes in health behavior, attitudes or psychological factors did not directly explain the changes in cardiovascular risk markers (e.g. triglycerides and waist circumference). However, change in the cardiovascular threat experience may have affected change in triglyceride values through the total and HDL cholesterol, which indicates that our message based on an EPPM model, was working correctly. It was also found that changes in some clinical factors accumulated, as seen in the BMI, which was the strongest predictor of the changes in triglycerides and waist circumference. The results imply that changes in health behaviors may not be reflected at a clinical level (within one year) or that they could depend on an optimistic bias effect 
or a variation in responses to dietary changes among ApoE genotypes. Clinical factors are important to include, because they may act as a 'control' for the self-assessed behavior changes (e.g. diet). Overall, it can be assumed that genetic screening, as a part of promoting lifestyle changes, will become more common and therefore, further research of those factors which affect the adoption and utilization of the genetic information, including a longer follow-up, is suggested.

\section{Human Studies and Informed Consent}

All procedures followed were in accordance with the ethical standards of the responsible committees on human experimentation (institutional and national) and with the Helsinki Declaration of 1975, as revised in 2000 [5]. Informed consent was obtained from all patients before being included in the study.

\section{Animal Studies}

No animal studies were carried out by the authors for this article.

\section{Acknowledgements}

First, we would like to thank all the participants in the study. We are grateful to the personnel of the Clinical Chemistry Department at the Central Hospital of Southern Ostrobothnia; the nutritionist, Hilpi Linjama M.Sc and all assistants in this study. Special acknowledgement goes to Sanja Laitila for her great value as regards her background knowledge of this study. Special thanks also to Jouko Katajisto, M.Sc. for his great help in all the statistical analyzes and Elizabeth Nyman, M.A for the scientific proofreading of this manuscript.

\section{Conflict of Interests}

The authors confirm that they have no conflict of interest. The Finnish Cultural Foundation, the Central Hospital of Southern Ostrobothnia (EVO 1140), the Aarne and Aili Turunen Foundation, and the European Regional Development Fund (EAKR) Project A31342 have funded the work. Hanna-Leena Hietaranta-Luoma MSc. prepared the manuscript. All authors critically reviewed the manuscript and approved the final version submitted for publication.

\section{References}

1. Lovegrove JA, Gitau R. Personalized nutrition for the prevention of cardiovascular disease: a future perspective. J Hum Nutr Diet. 2008; 21(4): 306-16. doi: 10.1111/j.1365-277X.2008.00889.x.

2. Bonnet F, Irving K, Terra JL, Nony P, Berthezène F, Moulin P. Anxiety and depression are associated with unhealthy lifestyle in patients at risk of cardiovascular disease. Atherosclerosis. 2005; 178(2): 339-44.

3. Collins RE, Lopez LM, Marteau TM. Emotional impact of screening: a systematic review and meta-analysis. BMC Public Health. 2011; 11: 603. doi: 10.1186/1471-2458-11-603.

4. Heshka JT, Palleschi C, Howley H, Wilson B, Wells PS. A systematic review of perceived risks, psychological and behavioral impacts of genetic testing. Genet Med. 2008; 10(1): 19-32. doi: 10.1097/ GIM.0b013e31815f524f.
5. Kim Witte, Gary Meyer, Dennis Martell. Effective Health Risk Message: A Step-by-Step Guide. California: Sage Publications; 2001.

6. Roininen K, Tuorila H, Zandstra EH, De Graaf C, Vehkalahti K, Stubenitsky K, et al. Differences in health and taste attitudes and reported behaviour among Finnish, Dutch and British consumers: a cross-national validation of the Health and Taste Attitude Scales (HTAS). Appetite. 2001; 37(1): 33-45.

7. Zandstra E., de Graaf C, Van Staveren W. Influence of health and taste attitudes on consumption of low- and high-fat foods. Food Quality and Preference. 2001; 12(1): 75-82.

8. Hearty AP, McCarthy SN, Kearney JM, Gibney MJ. Relationship between attitudes towards healthy eating and dietary behaviour, lifestyle and demographic factors in a representative sample of Irish adults. Appetite 2007, 48(1): 1-11.

9. Biltoft-Jensen A, Groth M V, Matthiessen J, Wachmann H, Christensen T, Fagt S. Diet quality: associations with health messages included in the Danish Dietary Guidelines 2005, personal attitudes and social factors. Public Health Nutr. 2009; 12(8): 1165-73. doi: 10.1017/ S1368980008003662.

10. Talvia $S$, Räsänen L, Lagström $H$, Anglè $S$, Hakanen $M$, Aromaa $M$, et al. Parental eating attitudes and indicators of healthy eating in a longitudinal randomized dietary intervention trial (the STRIP study). Public Health Nutr. 2011; 14(11): 2065-73. doi: 10.1017/ S1368980011000905.

11. Kraus SJ. Attitudes and the Prediction of Behavior: A Meta-Analysis of the Empirical Literature. Personality and Social Psychology Bulletin. 1995; 21(1): 58-75.

12. Hietaranta-Luoma HL, Hopia A, Luomala H, Puolijoki H. Using ApoE genotyping to Promote Healthy Lifestyles in Finland - Psychological Impacts: Randomized Controlled Trial. J Genet Couns. 2015.

13. Hietaranta-Luoma HL, Tahvonen R, Iso-Touru T, Puolijoki H, Hopia A. An Intervention Study of Individual, apoE Genotype-Based Dietary and Physical-Activity Advice: Impact on Health Behavior. J Nutrigenet Nutrigenomics. 2014; 7(3): 161-74. Epub 2015 Feb 20.

14. Hietaranta-Luoma HL, Åkerman K, Tahvonen R, Puolijoki H, Hopia A. Using Individual, ApoE Genotype-Based Dietary and Physical Activity Advice to Promote Healthy Lifestyles in Finland-Impacts on Cardiovascular Risk Markers. Open Journal of Preventive Medicine 2015, 05: 206-17.

15. Finnish Hearth Association. Test your fat quality; 2015.

16. Schuit AJ, van Loon AJM, Tijhuis M, Ocké MC. Clustering of Lifestyle Risk Factors in a General Adult Population. Prev Med. 2002; 35(3): 219-24.

17. Raitakari OT, Leino M, Räkkönen K, Porkka K V, Taimela S, Räsänen L, et al. Clustering of risk habits in young adults. The Cardiovascular Risk in Young Finns Study. Am J Epidemiol. 1995; 142(1): 36-44.

18. Artaud F, Dugravot A, Sabia S, Singh-Manoux A, Tzourio C, Elbaz A. Unhealthy behaviours and disability in older adults: Three-City Dijon cohort study. BMJ. 2013; 347: f4240. doi: 10.1136/bmj.f4240.

19. Robinson SM, Jameson KA, Syddall HE, Dennison EM, Cooper C, Aihie Sayer A. Clustering of lifestyle risk factors and poor physical function in older adults: The hertfordshire cohort study J Am Geriatr Soc. 2013; 61(10): 1684-91. doi: 10.1111/jgs.12457.

20. Poortinga W. The prevalence and clustering of four major lifestyle risk factors in an English adult population. Prev Med. 2007; 44(2): 124-8.

21. Pronk NP, Anderson LH, Crain AL, Martinson BC, O’Connor PJ, 
Sherwood NE, et al. Meeting recommendations for multiple healthy lifestyle factors: Prevalence, clustering, and predictors among adolescent, adult, and senior health plan members. Am J Prev Med. 2004; 27(2 Suppl): 25-33.

22. Lukasiewicz E, Mennen LI, Bertrais S, Arnault N, Preziosi P, Galan P, et al. Alcohol Intake in Relation to Body Mass Index and Waist-to-Hip Ratio: The Importance of Type of Alcoholic Beverage. Public Health Nutr. 2005; 8(3): 315-20.

23. Ma J, Betts NM, Hampl JS. Clustering of lifestyle behaviors: the relationship between cigarette smoking, alcohol consumption, and dietary intake. Am J Health Promot. 2000; 15(2): 107-17.

24. O'Neil CE, Nicklas TA, Myers L, Johnson CC, Berenson GS Cardiovascular risk factors and behavior lifestyles of young women: implications from findings of the Bogalusa Heart Study. Am J Med Sci. 1997; 314(6): 385-95.

25. Masson LF, McNeill G, Avenell A. Genetic variation and the lipid response to dietary intervention: a systematic review. Am J Clin Nutr. 2003; 77(5): 1098-111.

26. Miles S, Scaife V. Optimistic bias and food. Nutr Res Rev. 2003; 16(1): 3-19. doi: 10.1079/NRR200249.

27. Kearney JM, Gibney MJ, Livingstone BE, Robson PJ, Kiely M, Harrington
K. Attitudes toward and beliefs about nutrition and health among a random sample of adults in the Republic of Ireland and Northern Ireland: Application of logistic regression modelling. Public Health Nutr. 2001; 4(5A): 1117-26.

28. Lloyd HM, Paisley CM, Mela DJ. Changing to a low fat diet: attitudes and beliefs of UK consumers. Eur J Clin Nutr. 1993; (5): 361-73.

29.Glasman LR, Albarracín D. Forming attitudes that predict future behavior: a meta-analysis of the attitude-behavior relation. Psychol Bull. 2006; 132(5): 778-822.

30. Carvalho-Wells AL, Jackson KG, Lockyer S, Lovegrove JA, Minihane AM. APOE genotype influences triglyceride and C-reactive protein responses to altered dietary fat intake in UK adults. Am J Clin Nutr. 2012; 96(6): 1447-53. doi: 10.3945/ajcn.112.043240.

31. Current Care guidelines are independent, based on research evidence of national treatment recommendations. Dyslipidemias. 2015.

32. Geeroms N, Verbeke W, Van Kenhove P. Consumers' health-related motive orientations and ready meal consumption behaviour. Appetite. 2008; 51(3): 704-12. doi: 10.1016/j.appet.2008.06.011.

33. Hietaranta-Luoma HL, Karhu H, Eromäki H, Finne M, Luomala H, Nissinen K, et al. Lifestyles of South Ostrobothnians - What Are They like and Where Are We Now? Analysis Based on Identification of Consumer Groups with Varying Meanings of Health. Seinäjoki; 2011. 